\title{
Life-History Evolution, Human Impacts on
}

E Edeline, Sorbonne Universités/UPMC Univ Paris 06/CNRS/INRA/IRD/Paris Diderot Univ Paris 07/UPEC/Inst. d'Ecologie et des Sciences de l'Environnement - Paris (iEES-Paris), Paris, France

(C) 2016 Elsevier Inc. All rights reserved.

\section{Glossary}

Adaptive landscape Relationship between fitness and trait(s) under selection ( = fitness landscape).

Fitness Individual contribution to the genetic pool of the next generation ( $=$ relative reproductive success).

Response to selection Change in mean trait value(s) in a population due to selection. Response to selection operates through the transmission of heritable information (nucleic acids, hormones, knowledge...) from one generation to the next. Selection The process through which environmental conditions generate fitness variation among individuals. Selection operates on different units of selection corresponding to the different levels of biological organization (genes, cells, individuals...).

\section{Introduction}

The expansion of agriculture about 10000 years ago allowed the settlement and growth of human populations, and from there the development of cities and of a social organization (civilization) that promoted technological innovations. Together, the human demographic expansion and technological improvements are the main drivers of so-called 'anthropogenic changes,' the perturbations brought about by human activities on natural systems.

Fundamentally, anthropogenic perturbations on natural systems simply arise from resource consumption by humans. However, its manifestations are multiple and interconnected, among which are often reported landscape alterations, soil deterioration, disruption of geochemical cycles, climate warming, or over-harvesting. All of these perturbations almost inevitably alter, directly or indirectly, the selective pressures acting on organisms.

Impacted populations must respond to these anthropogenic selective pressures by evolving life histories that are more fit to the newly selected, composite adaptive landscape that results from the combination of natural and anthropogenic selection. This response is the subject of the present article. If the response is too slow to track changes in the selective pressures, the population goes instinct. This failure to adapt is the underlying cause of the global biodiversity loss currently experienced by the earth ecosystems.

First, in this article, basic theory of selection and response to selection is recalled, then a specific focus on three major sources of anthropogenic selection (harvesting, habitat fragmentation, and temperature increase) is provided, and finally it is examined how rapid life-history evolution may change natural selection acting back on life histories, the so-called eco-evolutionary feedback loop.

\section{Selection and Response to Selection}

\section{Natural and Anthropogenic Sources of Selection}

In this article only selection acting on individuals transmitting genes to their offspring will be considered, because the individual is the level of selection having received the most thorough treatment in the literature (for a broader perspective see Wilson and Sober, 1994), and because genes represent the most widespread 70 support of heredity (for non-genetic inheritance, see Danchin, 2013). Selection of individuals may be 'natural' or 'artificial' depending on whether it results from nonhuman or from anthropogenic factors, respectively. To illustrate this, let me consider the case of pike (Esox lucius) in Windermere, the largest natural lake in England.

In Windermere, scientists have conducted long-term markrecapture experiments on pike (Le Cren, 2001). The resultant data has allowed the computation of a component of natural selection, namely the form of the relationship between survival and body size (Haugen et al., 2007; Carlson et al., 2007; Vindenes et al., 2014). This relationship shows that natural selection favors large-sized pike up to a body length of about $60 \mathrm{~cm}$ (blue solid line in Figure 1), after which survival is likely to remain constant (Vindenes et al., 2014). A larger size likely provides pike with access to more resources, increased protection against cannibals and other predators, and increased energy stores to survive to winter fasting (Edeline et al., 2007; Vindenes et al., 2014). From this relationship, we may predict that there is a directional natural selection for rapidly reaching a body length of about $60 \mathrm{~cm}$ in Windermere pike.

In parallel with mark-recapture experiments, scientists have also submitted pike to gillnet fishing since the early 1940s (Le Cren, 2001). All pike captured in the gillnet fishery are killed, measured for several biological variables, and their opercular bones are removed. These bones record the age of each fish in the form of annuli (like in a tree trunk), and the radius of these annuli are proportional to individual body length, thus allowing the back calculation of length-at-age. From this information, it was possible to model the link between body length and the probability for a fish to be captured in the fishery. This relationship is depicted in Figure 1 (red dashed line), which shows that the probability for a pike to be caught in the gillnet fishery suddenly increases after a body length of $50 \mathrm{~cm}$. Hence, we predict that there is a directional anthropogenic selection for growing slowly so as to remain smaller than about $50 \mathrm{~cm}$ in Windermere pike. 


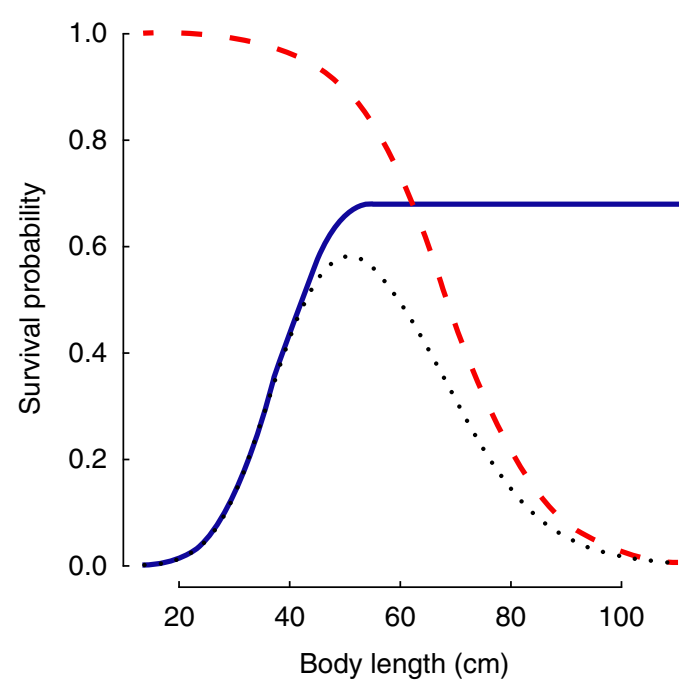

Figure 1 Size-dependent survival probability of Windermere pike (Esox lucius) through the directional components of natural selection (blue solid line) and the gillnet fishery (red dashed line). The resultant composite survival curve (the product of the two functions) is represented with the black dotted line and shows stabilizing selection around an adaptive peak at about $50 \mathrm{~cm}$. The natural survival function was computed following Vindenes et al. (2014).

Combining these two (natural and anthropogenic) sources of selection acting on the body size of Windermere pike reveals the composite adaptive landscape, which reflects the truly experienced selective regime (black dotted line in Figure 1). We see that this composite landscape is very different from the naturally selected landscape. Anthropogenic selection decreases the overall area below the curves, i.e., it decreased overall survival probability of pike. This is predicted to induce an evolutionary response toward faster life histories in the pike population (see section Non-phenotypically Selective Harvesting of this article).

However, this increase in mortality is nonrandom, but instead biased toward large-sized pike, thus further reinforcing directional selection toward smaller sizes and faster life histories (see section Phenotypically selective harvesting of this article). This biased mortality is visible in that anthropogenic selection generates an adaptive peak (i.e., stabilizing selection) around a body length of $50 \mathrm{~cm}$. Let us now more closely examine how response to these sources of selection may be qualitatively predicted.

\section{Response to Directional Selection}

Predicting response to selection is the central purpose of quantitative genetics theory (Lynch and Walsh, 1998). This theory predicts that dynamic response to selection of a single trait having negligible genetic covariance with other fitness traits obeys the equation:

$$
\bar{\chi}_{t+1}=\bar{\chi}_{t}+R_{\chi}
$$

where $\bar{\chi}_{t+1}=$ mean value of trait $x$ in the population at generation $t+1, \bar{\chi}_{t}=$ mean value of trait $x$ in the population at generation $t$, and $R_{\chi}=$ response to selection in trait $\chi$, that may be recast as:

$$
R_{\chi}=H_{\chi} S_{\chi}=\frac{V a_{\chi}}{V p_{\chi}} S_{\chi}=V a_{\chi} \frac{\partial w_{\chi}}{\partial_{\chi}}
$$

where $H_{\chi}=\mathrm{V} a_{\chi} / V p_{\chi}=$ narrow-sense heritability for the trait where $V a_{\chi}=$ additive genetic variance and $V p_{\chi}=$ phenotypic variance (with $V p_{\chi} \geq V a_{\chi}$ ), and $S_{\chi}=\bar{\chi}_{a}-\bar{\chi}_{b}=$ net directional selection differential where $\bar{\chi}_{a}=$ mean trait value in the population after selection and $\bar{\chi}_{b}=$ mean trait value in the population before selection. Here, following Lande and Arnold (1983) the equation is rearranged to obtain the directional selection gradient $\left(\bar{\chi}_{a}-\bar{\chi}_{b}\right) / V p_{\chi}=\partial w_{\chi} / \partial_{\chi}$, where $w_{\chi}=$ relative fitness of an individual with trait $x$.

Note that eqn [1b] makes the assumption that $V a_{\chi}$ is independent of $S_{x}$, which is not true if directional selection drives allelic frequencies toward 0 or 1 in the population (see section Evolvability of this article). In such a case, eqn [1b] can be used only to predict short-term response to selection. Additionally, eqn [1b] is often used by considering $S_{\chi}$ as a constant, which may be true when one considers artificial selection only, but which is wrong when trait change alters natural selection acting on that trait - the so-called ecoevolutionary feedback loop (see section Change in the naturally selected adaptive landscape of this article).

However, despite these shortcomings, eqn [1b] remains conceptually very useful in that it clearly shows that evolution of a life-history trait requires that both $V a_{\chi}>0$ and $\delta w_{\chi} / \delta_{\chi} \neq 0$, and that the speed of evolution is proportional to the values of these two components. Generally, $V a_{\chi}>0$ for life-history and morphological traits (Mousseau and Roff, 1987), which are thus highly susceptible to respond to anthropogenic directional selection. Let us now concentrate on reviewing some of the current knowledge on such responses.

\section{Evolutionary Response to Harvesting}

Humans have harvested wild plant and animal species since they appeared on earth. Hunting by human populations is thought to have played a role in the late Pleistocene (15000 years ago) extinctions of large terrestrial mammals in Australia, North America, and South America (Barnosky et al., 2004). The development of agriculture has made humans less dependent upon wild plant and animal resources, but the parallel rise in the human population and progress in harvesting technologies has also tremendously increased the pressure on those populations that remain exploited. The overexploitation problem is mostly documented in fish and mammals, but it may arise in any animal or plant population. Here, we will consider separately the effects of nonphenotypically selective and phenotypically selective harvesting.

\section{Non-Phenotypically Selective Harvesting}

Non-phenotypically selective harvesting adds a mortality component to the natural mortality background uniformly in all age or size classes, and thus provides a gain in relative fitness to early-maturing individuals which have a higher 
probability to reproduce before being killed (Abrams and Rowe, 1996).

If maturation (and reproductive allocation) conflicts with somatic growth due to physiological or ecological trade-offs, then harvesting also induces a decrease in somatic growth rates. Similarly, trade-offs may occur between reproduction and somatic maintenance, so that we may expect to also observe increased senescence in exploited populations. Accordingly, a number of studies have demonstrated that reproduction incurs a cost in terms of somatic growth (Roff, 1992), predation risk (Magnhagen, 1991), or immune capacity (Zuk and Stoehr, 2002). A cost of reproduction in terms of senescence (Williams, 1957) has received more contrasted support (Reznick et al., 2004).

\section{Phenotypically Selective Harvesting}

Harvesting is almost always phenotypically selective. Harvesters often target larger and older individuals due to their higher market or trophy values, and/or due to regulatory rules that impose a minimum size limit to the catch. Compared to non-size-selective harvesting, this biased mortality further strengthens the relative advantage for an early maturation, and also directly selects for slower somatic growth because larger individuals are often faster growers (Biro and Post, 2008). In line with this theoretical prediction, earlier maturation and/or smaller body size in response to harvesting have been documented in a variety of wild, exploited populations.

Size-related trait change in exploited populations are on average 3 times faster than in unexploited populations, and results in $20 \%$ smaller traits on average (Darimont et al., 2009). For instance, in the snow lotus (Saussurea laniceps), plant cropping for medicine has induced a decrease in mean plant size from about $30 \mathrm{~cm}$ in 1900 to about $20 \mathrm{~cm}$ in the 2000s (Law and Salick, 2005). In the bighorn sheep (Ovis canadensis), mean body weight of rams has declined from 85 to $65 \mathrm{~kg}$ from 1975 to 2005 due to trophy hunting, while mean horn sizes have decreased from about 70 to $50 \mathrm{~cm}$ (Coltman et al., 2003). In the pink salmon (Oncorhynchus gorbuscha), weight at spawning (age 2) has decreased by up to $34 \%$ from the 1950 s to the 1990 s (McAllister et al., 1992). In the Canadian Altlantic cod, female length at 50\% maturation probability dwindled from about $65 \mathrm{~cm}$ (and 7 years of age) in the early 1950s to about $40 \mathrm{~cm}$ (and 4.5 years of age) in the early 1990s, and remained at this low level up to the early 2000s (Olsen et al., 2004; Swain, 2011). On longer time scales, decrease in mean body size may be even larger. Archeological records of skeletal parts suggest that mean body size of cod in the Gulf of Maine (USA) has decreased from 100 to $30 \mathrm{~cm}$ due to overfishing (Jackson et al., 2001).

Harvest-induced evolution is sometimes (maybe abusively) termed 'maladaptive,' because it may drive the population far from its naturally selected adaptive peak (i.e., evolution is maladaptive relative to natural selection acting alone). This 'maladaptive' evolution simply reflects a severe reduction in fitness due to anthropogenic selection. For instance, in Atlantic cod (Gadus morhua), earlier maturation at a smaller size in response to fishing is expected to increase the mortality cost of reproduction. A reduction of age at maturity from 6 to 4 years projects into a $25-30 \%$ decrease in population growth rate (Hutchings, 2005). This decrease in fitness may be linked to increased reproductive mortality (Hutchings, 2005; Swain, 2011), as well as changes in traits correlated with body size. For instance, selection against a large body size in Atlantic silverside (Menidia menidia) depresses fecundity, egg volume, larval size at hatch, larval viability, larval growth rates, food consumption rate, and conversion efficiency (Walsh et al., 2006).

\section{Evolutionary Response to Habitat Loss and Fragmentation}

Habitat loss and fragmentation often result from 'modern' agricultural practices, road building or, more dramatically, from urbanization. Habitat loss is a primary cause of species extinction, indicating that the generated selective pressures are so strong that many populations can simply not adapt. Habitat fragmentation, in contrast, may allow species to persist, but tend to change large homogeneous populations into metapopulations, i.e., a population of populations between which individuals may disperse (Levins, 1969; Pulliam, 1988). Here, I consider how anthropogenic habitat fragmentation may affect life histories through selection acting on body size and on dispersal ability.

\section{Size-Dependent Selection}

Although many studies have linked a large body size with an increased extinction risk in response to anthropogenic perturbations (Purvis et al., 2000; Cardillo et al., 2005; Van Allen et al., 2012), the link between body size and sensitivity to habitat perturbation is not clear (Henle et al., 2004). This lack of evidence for size-dependent selection might come from conflicting selective pressures.

Large animals have large home ranges (Peters, 1983; Jetz et al., 2004), and are thus more likely to be impacted by the fragmentation and loss of their vital habitat. For instance, carnivores in protected areas primarily die from 'edge effects,' i.e., due to conflicts with humans on reserve borders (Woodroffe and Ginsberg, 1998). In the Amazonian forest, fragmentation-induced edge effects magnify the negative impact of hunting on medium-sized and large vertebrates (Peres, 2001). Additionally, a large body size is associated with small population sizes (Woodward et al., 2005). Hence, in a context of reduced habitat availability, large-bodied species may rapidly reach population sizes at which demographic stochasticity elevates extinction risk. Finally, because habitat perturbation imposes so strong selective pressures, population persistence critically depends on the capacity of the population to adapt (or disperse, see below). However, a large body size requires a long development time (i.e., long generation time), and thus imposes slow life histories and slow rates of adaptive evolution. In parallel with selection against a large body size, habitat perturbation may also select against a small body size. A small size is associated with a narrower range of prey sizes, reduced trophic generalism (Woodward et al., 2005), and possibly also with an increased habitat specialization. 
Accordingly, this link between a small body size, habitat specialization, and increased sensitivity to habitat loss was found in birds (Owens and Bennett, 2000) and freshwater fish (Olden et al., 2007), but the underlying drivers remain unclear. Therefore, the net overall effect of habitat fragmentation might be to select against both small and large body sizes, ultimately favoring medium-sized individuals and species. More research is needed to test this hypothesis.

\section{Dispersal-Dependent Selection}

Dispersal generally brings a selective advantage in heterogeneous environments, where the environment is understood in terms of the ecological niche (Hutchinson, 1957). Hence, anthropogenic selection for increased dispersal propensity occurs when habitat fragmentation increases habitat heterogeneity in space and time. In particular, smaller patch sizes are likely to amplify population fluctuations due to increased demographic stochasticity (from smaller population sizes), elevate the temporal heterogeneity of the environment, and ultimately result in increased selection for dispersal (Parvinen et al., 2004).

In turn, dispersal-dependent selection may induce the evolution of life-history traits correlated with dispersal (Roff and Fairbairn, 2001). For instance, the sand cricket (Gryllus firmus) shows a genetically based trade off between flight allocation and reproductive allocation (King et al., 2011), indicating that selection for dispersal will also induce evolution towards reduced reproductive investment. In insects and fish, an increased ability for long-distance dispersal is often positively associated with a large body size, because a larger size increases the energetic efficiency of movement (Roff, 1991). Hence, anthropogenic selection for increased long-distance dispersal may indirectly select for a large body size, and is thus expected to interact with direct size-dependent selection (see previous section).

However, anthropogenic habitat fragmentation may also increase dispersal mortality and select against dispersal traits. Hence, the counteracting effects of landscape fragmentation on the evolution of dispersal and life histories may give rise to complex evolutionary dynamics when realistic ecological complexity is accounted for (Parvinen et al., 2004). This complexity might be responsible for an often reported absence of a link between dispersal-dependent selection and life-history evolution (Ronce and Clobert, 2012).

\section{Evolutionary Response to Climate Warming}

Temperature determines the rate of metabolic reactions and is a key driver of individual physiology (Brown et al., 2004). Warmer ambient temperatures have been repeatedly reported to favor smaller body sizes and faster life histories in both endotherms and ectotherms (Angilletta, 2009), a phenomenon dubbed 'Bergmann's Rule' (BR) in endotherms and temperature-size rule (TSR) in ectotherms (Atkinson, 1994).

BR posits that heat loss of an endotherm organism is proportional to its body surface-to-volume ratio. Because body volume increases faster than body surface area with increasing body size, there is a selective advantage to a small body size (higher body surface-to-volume ratio and easy heat loss) in warm areas, and conversely to a large body size in colder climates (lower body surface-to-volume ratio and reduced heat loss).

The thermodynamic argument proposed by Bergmann for endotherms does not hold for ectotherms, and the underlying drivers of the TSR remain far from clear (Angilletta, 2009). Proximate mechanisms so far proposed to explain the TSR include a higher thermal sensitivity of gonad growth rate than body growth rate, resulting in an increased fraction of energy allocated to gonads under warmer temperatures (Van der Have and de Jong, 1996; Zuo et al., 2011), and/or smaller sizes of cells and genome at higher temperature (Partridge et al., 1994; Hessen et al., 2013), and/or limitation of oxygen path length at higher body sizes (Pörtner and Knust, 2007; Forster et al., 2012). Ultimate (adaptive) mechanisms include increased mortality and/or higher population rate of increase at higher temperatures (Sibly and Atkinson, 1994).

However, none of these mechanisms has yet been shown to be universal. Recently, however, there has emerged the idea that different thermal sensitivities of ingestion and maintenance rates may drive a competition-mediated selective advantage for small-bodied individuals under warm conditions (Ohlberger et al., 2011; Reuman et al., 2014; Edeline et al., 2013). To understand the arguments it is necessary to start from the $R^{*}$ theory of exploitative competition (Tilman, 1982), adapted to account for the size-dependency of resource consumption and metabolic rates (Persson et al., 1998; De Roos et al., 2003).

In this framework, resource-dependent variations in individual body mass $\mathrm{d} B / \mathrm{d} t$ are given by:

$$
\frac{\mathrm{d} B}{\mathrm{~d} t}=\operatorname{Fr}(R)-m=a R-m
$$

where $\mathrm{d} B / \mathrm{d} t$ is also equivalent to individual fitness since mass gain can be invested in reproduction, $a=$ attack or intake rate in a Holling's type I functional response, and $m=$ maintenance metabolic rate. Equilibrium, i.e., null fitness, occurs at $R=R^{*}$ such that $R^{*}=m / a$, i.e., where resource density makes $a R^{*}$ equal to $m$ (Figure 2). Just as in Tilman's (1982) theory, the individual having the lowest $R^{*}$ wins the competition and excludes the others that starve to death (Persson et al., 1998).

Biological rates usually follow power allometric exponents (Peters, 1983; Brown et al., 2004), such that the relationship between $R^{*}$ and body size can be written:

$$
R^{*}=\frac{m}{a}=\frac{\mu B^{\gamma}}{\alpha B^{\delta}}=\frac{\mu}{\alpha} B^{\gamma-\delta}
$$

where $\mu, \alpha, \gamma$, and $\delta$ are positive constants. Equation [3] shows that whether $R^{*}$ increases or decreases with an increasing body mass, $B$ depends on the sign of the $\gamma-\delta$ difference. If maintenance metabolic rate increases faster with increasing body mass than intake rate, i.e., if $\gamma>\delta$, then $R^{*}$ increases with increasing body mass, small individuals dominate large individuals in exploitative competition (Persson et al., 1998; De Roos et al., 2003; Persson and De Roos, 2006), and low resources select for smaller body sizes. Resource-poor environments select for reduced somatic growth rates (i.e., select for smaller body sizes) in a variety of taxa (Arendt, 1997), suggesting that an increase of $R^{*}$ with body size is common. 


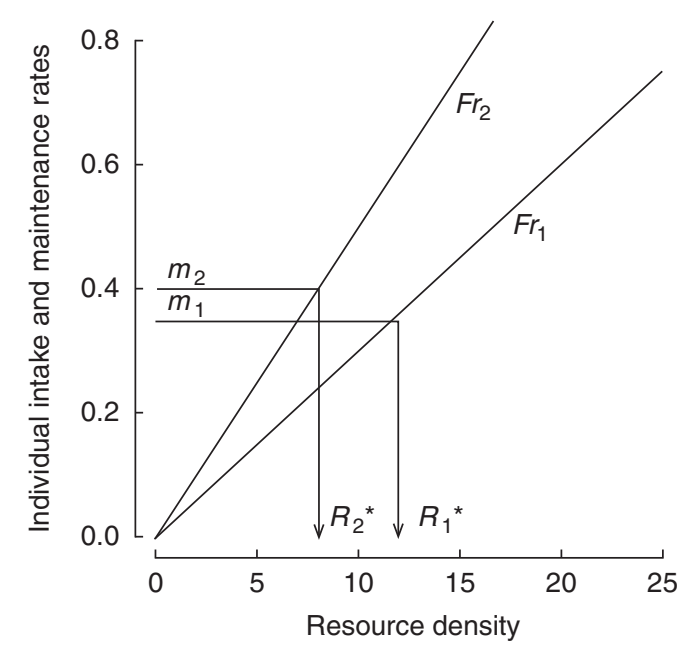

Figure 2 The $R^{*}$ rule for two individual consumers competing for the same resource $R$. Resource intake rate is represented by a Holling's type I functional response $F r$, while maintenance rate $m$ is resource-independent. Zero growth (equivalent to null fitness in eqn 2) occurs where $R=R^{*}$. The individual having the lowest $R^{*}$ (here individual 2) wins the competition. Reproduced from Tilman, D., 1982. Resource Competition and Community Structure. Princeton, NJ: Princeton University Press.

However, $R^{*}$ decreases with body size in waterflies Daphnia sp. (Gliwicz, 1990), suggesting that filter-feeding organisms - and maybe generally organisms having a Holling's type I functional response - might constitute an exception. More research is needed to clarify this question.

Biological rates are in fact not just size- but also temperaturedependent (Gillooly et al., 2001). The effects of temperature on intake and maintenance rates included in eqn [3], and thus on and its size dependency, are poorly understood. It was shown in a physiologically-structured model tailored for Eurasian perch Perca fluviatilis that higher temperatures may increase the advantage of small against large individuals in exploitative competition (Ohlberger et al., 2011). Hence, climate warming seems to increase in large individuals relative to small individuals. Reuman et al. (2014) and Edeline et al. (2013) came to a similar conclusion in unicellular phytoplankton and river fish communities (52 species), respectively. Finally, Vindenes et al. (2014) showed in Windermere pike that this temperaturedependent $R^{*}$ selection translated into accelerated juvenile growth and decreased survival of large individuals, such that the proportion of medium-sized individuals increased in the population. More details about warming-induced selective pressures acting on life-history traits may be found in the chapter An Age- and Length-Structured Life History Model for Pike, a Top Predator in Freshwater Ecosystems (00094) by Yngvild Vindenes. Taken together, these results call for an increased focus on size-dependent exploitative competition in climate-warming research.

\section{Reversibility of Trait Changes and Population Recovery}

A natural management response to human-induced ecological problems is to relax the source of perturbation, so that the ecosystem may return to its initial state. However, not all sources of perturbation are easily relaxed. In case of habitat loss and fragmentation, backward re-naturalization of urbanized or agricultural habitats requires will power and investments that often go beyond the capacities of local managers. This problem is even more insurmountable when it comes to reversing the global trend toward increased production of greenhouse gas and the parallel global warming.

Hence, most examples of relaxed anthropogenic forcing on life histories come from harvested systems. In particular, fisheries provide us with reassuring examples of systems that return to their initial state (rebound) after fishery relaxation or closure, but also with the worrying cases of systems that do not recover (stasis). Let us here concentrate on the possible causes of stasis (for rebounds, see Edeline et al., 2007; Edeline et al., 2009; Conover et al., 2009 and Frank et al., 2011). Evolutionary stasis has two possible sources: a loss of evolvability for life-history traits and/or a change in the natural selective pressures acting on life histories.

\section{Evolvability}

Equation [1b] assumes for simplicity that additive genetic variance (evolvability) and selection differentials are independent, such that the trait can endlessly evolve. However, in theory evolvability and selection are not independent because intense directional selection should exhaust additive genetic variance and impair reversibility of trait changes, unless genetic variation is constantly renewed (Crow, 2008). This gave rise to concern about a potential loss of evolvability in heavily exploited populations (Hutchings and Fraser, 2008), and might explain why some fish stocks have problems to recover even after the relaxation of exploitation rates (Hutchings and Reynolds, 2004; Frank et al., 2005; Swain, 2011). In these stocks, relaxation of fishing would reestablish the naturally selected phenotypic optimum (i.e., $\delta w_{\chi} / \delta_{\chi} \neq 0$ in eqn [1b]), but traits could not follow due to lack of genetic variability (i.e., $V a_{x} \rightarrow 0$ in eqn [1b]). Is this a credible hypothesis?

The tremendous phenotypic diversity of formerly wild, now domestic animals (e.g., dogs, pigeons, chicken, ...) or plants (roses, cereals, ...) suggests that genetic diversity hardly limits the range of possible phenotypes under captive conditions. For instance, maize (Zea mays) still responds to strong bidirectional selection on oil and protein concentration in grains since more than 100 generations (Moose et al., 2004). Similarly, white Plymouth Rock chickens continued to respond to bidirectional selection on body weight at 8 weeks of age since 54 generations (Dunnington et al., 2013). At generation 54, males weighted on average $2 \mathrm{~kg}$ in the high-selected lines versus $0.173 \mathrm{~kg}$ in the low-selected lines, respectively ( 1.380 vs. $0.129 \mathrm{~kg}$ in females). These examples from domestic populations suggest that additive genetic variance often persists, even under severe directional selection (Crow, 2008). But what about wild populations?

A fundamental difference between captive and wild conditions is natural selection. If anthropogenic and natural selection act in opposition (Figure 1), then overall selective pressures are no longer directional but stabilizing, and stabilizing selection may erode trait genetic variance even more 
rapidly than directional selection. However, in Windermere pike, the overall form of fishing-induced selection was in fact not directional (as presented for simplicity in Figure 1) but disruptive (Carlson et al., 2007), which is typical for gillnets (Lagler, 1968). Consequently, scientific gillnet fishing for pike in Windermere, whose intensity was mild (mean exploitation rate was $6.5 \%$ per year \pm 4.7 SD (Langangen et al., 2011)), was associated with an increased variability for length-at-age in the population, and thus presumably increased genetic variance for body size in the pike population (Edeline et al., 2009).

In contrast with scientific fishing, commercial fishing may impose very high exploitation rates (Hutchings (2000) reports reductions of $45-99 \%$ in reproductive biomass), in which case medium-sized individuals probably have no chance to reach a large size, even if harvest-induced selection is disruptive. Hence, in many situations anthropogenic selection likely generates strong directional selection acting in opposition with natural selection (Figure 1), and resulting in magnified stabilizing selection with a great potential for eroded genetic variance in body size and associated traits. To date, no empirical study has specifically explored the effects of commercial harvest on the genetic variability of fitness-related traits (for neutral genetic markers see for instance Allendorf et al., 2008; Pinsky and Palumbi, 2014), and this obviously represents an important gap in our knowledge.

\section{Change in the Naturally Selected Adaptive Landscape}

If a loss of adaptive genetic variability for body size and correlated traits is not involved (i.e., $V a_{x}>0$ in eqn [1b]), impediment to the recovery of exploited populations necessarily results from a change in natural selection (i.e., $\delta w_{\chi} / \delta_{\chi} \rightarrow 0$ in eqn [1b]). It has been argued that natural selection toward the phenotypic optimum is likely to be much weaker than harvestinduced selection away from it (Law, 2000; Enberg et al., 2009). However, weak natural selection is incompatible with the fact that harvest-induced evolution incurs severe fitness costs (see above). Instead, as a population phenotype evolves away from the naturally selected optimum, the strength of natural selection toward the optimum should increase. A more likely hypothesis to explain impediment to recovery involves a fishinginduced change in the naturally selected optimum itself.

This idea is well illustrated by a study by Douglas Swain on cod (Gadus Morhua) in the southern Gulf of Saint Lawrence (Swain, 2011). This cod stock, like several other Canadian cod stocks, has collapsed during the early 1990s in parallel with a rapid decrease in age and size at maturity, which presumably represented a response to fishing-induced selection (Olsen et al., 2004). However, despite severe reductions in the fishing pressure, age and size at maturity remained low in this stock and apparently did so because of an increase in natural mortality (Swain, 2011). Hence, the fishery seems to have changed the ecological conditions, shifting the naturally selected adaptive landscape of cod such that a faster life history is now the new adaptive optimum. This important result requires that we now examine what ecological changes may cause this shift in the naturally selected adaptive landscape.

Swain (2011) points to potential candidate mechanisms for increased natural mortality in southern Gulf of St. Lawrence cod. First, increased reproductive investment (as initially favoured by a high fishing mortality), together with low food conditions (Shelton et al., 2006), might have caused an increase in reproductive mortality. This hypothesis is supported by the fact that post-fishery increase in natural mortality mainly affected cod older than 5 years, i.e., reproductively active cod (Swain, 2011). Second, cod collapse was paralleled by an increase in the number of gray seals (Halichoerus grypus), which are predators for cod. However, seals tend to prey on juvenile cod, while the increased natural mortality effectively affected mainly adult cod (Chouinard et al., 2005), suggesting that predation from seals might not be a major cause of the now high natural mortality in adult cod.

We may propose additional mechanisms for increased mortality in adult cod. Cod and seals might in fact interact through intraguild predation (IGP), a type of interaction in which predators and prey also compete for common food sources (Holt and Polis, 1997). Hence, increased seal numbers might thus participate in depleting food resources for adult cod, and thus favor starvation during energy-demanding reproductive periods. Other species probably interact with cod through IGP. For instance, in the North Sea, herring (Clupea harengus) - a prey for cod - inhibits cod recruitment through competition with juvenile cod for zooplankton, but also through predation on cod eggs and larvae (Fauchald, 2010). In the southern Gulf of St. Lawrence cod, increased adult cod mortality possibly operated through exploitative competition from smaller-sized (i.e., lower R-starred) fish species that may also be prey for cod. Hence fishing for cod might have pushed an initially cod-abundant system to a new, stable but cod-sparse system in which selection favors smaller-sized cod (Abrams, 2011).

The cod example highlights the potential for eco-evolutionary feedback loops in human-perturbed ecosystems (Figure 3). These feedback loops act through density- or frequency-dependent natural selection, and are of crucial importance if one wants to correctly manage natural populations

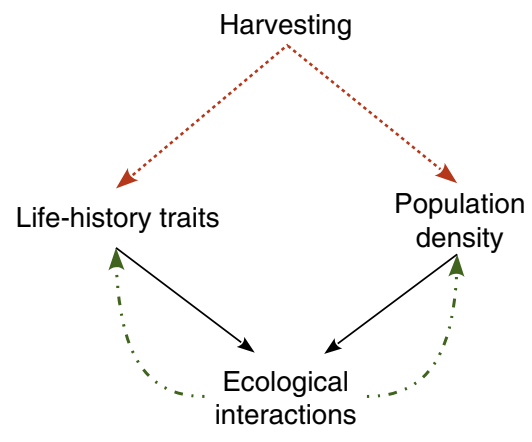

Figure 3 Density-dependent feedback loops arising from harvesting wild populations. Harvest-induced selection (dashed red arrows) favor in parallel faster life histories and reduced population density, which both potentially alter the strength or even nature of intra- and interspecific interactions (solid black arrows). Ultimately, natural selection acting through these ecological interactions (dotted and dashed green arrows) may feedback on life histories and population densities to either oppose (stabilizing eco-evolutionary feedback loop) or reinforce (runaway eco-evolutionary feedback loop) the effects of anthropogenic selection. 
(Dieckmann and Ferriere, 2004). A natural selection opposing the effects of anthropogenic selection results in a stabilizing feedback loop, helps in maintaining the system under control, and fosters recovery when the perturbation has ceased. However, in some cases (e.g., cod) natural selection may instead reinforce anthropogenic selection, accelerate change to a new population or ecosystem state, and impede reversal to the initial state. Hence, eco-evolutionary feedback loops stress the need to fully integrate food-web interactions and life-history theory in the next generation conservation plans.

See also: Evolvability, Quantitative Genetics of. Life History: Pike. Natural Selection, Measuring. Responses to Climate Change, Evolution and

\section{References}

Abrams, P.A., 2011. Simple life-history omnivory: Responses to enrichment and harvesting in systems with intraguild predation. The American Naturalist 178 305-319. doi:10.1086/661243

Abrams, P.A., Rowe, L., 1996. The effects of predation on the age and size of maturity of prey. Evolution 50, 1052-1061. doi:10.2307/2410646.

Allendorf, F.W., England, P.R., Luikart, G., Ritchie, P.A., Ryman, N., 2008. Genetic effects of harvest on wild animal populations. Trends in Ecology \& Evolution 23, 327-337. doi:10.1016/j.tree.2008.02.008.

Angilletta, Jr., M.J., 2009. Thermal Adaptation: A Theoretical and Empirical Synthesis. Oxford: Oxford University Press.

Arendt, J.D., 1997. Adaptive intrinsic growth rates: An integration across taxa. The Quarterly Review of Biology 72, 149-177.

Atkinson, D., 1994. Temperature and organism size - A bilogical law for ectotherms? In: Begon, M., Fitter, A.H. (Eds.), Advances in Ecological Research. Academic Press, pp. 1-58.

Barnosky, A.D., Koch, P.L., Feranec, R.S., Wing, S.L., Shabel, A.B., 2004. Assessing the causes of late Pleistocene extinctions on the continents. Science 306, 70-75. doi:10.1126/science.1101476.

Biro, P.A., Post, J.R., 2008. Rapid depletion of genotypes with fast growth and bold personality traits from harvested fish populations. Proceedings of the National Academy of Sciences of the United States of America 105, 2919-2922. doi:10.1073/pnas.0708159105.

Brown, J.H., Gillooly, J.F., Allen, A.P., Savage, V.M., West, G.B., 2004. Toward a metabolic theory of ecology. Ecology 85, 1771-1789. doi:10.1890/03-9000.

Cardillo, M., Mace, G.M., Jones, K.E., et al., 2005. Multiple causes of high extinction risk in large mammal species. Science 309, 1239-1241. doi:10.1126/ science 1116030.

Carlson, S.M., Edeline, E., Asbjørn Vøllestad, L., et al., 2007. Four decades of opposing natural and human-induced artificial selection acting on Windermere pike (Esox lucius). Ecology Letters 10, 512-521. doi:10.1111/j.1461-0248.2007.01046.x.

Chouinard, G.A., Swain, D.P., Hammil, M.O., Poirier, G.A., 2005. Covariation between grey seal (Halichoerus grypus) abundance and natural mortality of cod (Gadus morhua) in the southern Gulf of St. Lawrence. Canadian Journal of Fisheries and Aquatic Sciences 62, 1991-2000. doi:10.1139/f05-107.

Coltman, D.W., O'Donoghue, P., Jorgenson, J.T., et al., 2003. Undesirable evolutionary consequences of trophy hunting. Nature 426, 655-658. doi:10.1038/ nature02177.

Conover, D.O., Munch, S.B., Arnott, S.A., 2009. Reversal of evolutionary downsizing caused by selective harvest of large fish. Proceedings of the Royal Society of London. Series B, Biological Sciences 276, 2015-2020. doi:10.1098/ rspb.2009.0003.

Crow, J., 2008. Maintaining evolvability. Journal of Genetics 87, 349-353. doi:10.1007/s12041-008-0057-8.

Danchin, É., 2013. Avatars of information: Towards an inclusive evolutionary synthesis. Trends in Ecology and Evolution 28, 351-358. doi:10.1016/ j.tree.2013.02.010.

Darimont, C.T., Carlson, S.M., Kinnison, M.T., et al., 2009. Human predators outpace other agents of trait change in the wild. Proceedings of the National
Academy of Sciences of the United States of America. doi:10.1073/ pnas.0809235106.

De Roos, A.M., Persson, L., McCauley, E., 2003. The influence of size-dependent life-history traits on the structure and dynamics of populations and communities. Ecology Letters 6, 473-487. doi:10.1046/j.1461-0248.2003.00458.x.

Dieckmann, U., Ferrière, R., 2004. Adaptive dynamics and evolving biodiversity. In: Ferrière, R., Dieckmann, U., Couvet, D. (Eds.), Evolutionary Conservation Biology, first ed. Cambridge, MA: Cambridge University Press, pp. 188-224.

Dunnington, E.A., Honaker, C.F., McGilliard, M.L., Siegel, P.B., 2013. Phenotypic responses of chickens to long-term, bidirectional selection for juvenile body weight-historical perspective. Poultry Science 92, 1724-1734. doi:10.3382/ ps.2013-03069.

Edeline, E., Carlson, S.M., Stige, L.C., et al., 2007. Trait changes in a harvested population are driven by a dynamic tug-of-war between natural and harvest selection. Proceedings of the National Academy of Sciences of the United States of America 104, 15799-15804. doi:10.1073/pnas.0705908104.

Edeline, E., Lacroix, G., Delire, C., Poulet, N., Legendre, S., 2013. Ecological emergence of thermal clines in body size. Global Change Biology 19, 3062-3068. doi:10.1111/gcb.12299.

Edeline, E., Le Rouzic, A., Winfield, I.J., et al., 2009. Harvest-induced disruptive selection increases variance in fitness-related traits. Proceedings of the Royal Society of London. Series B, Biological Sciences 276, 4163-4171. doi:10.1098/ rspb.2009.1106.

Enberg, K., Jørgensen, C., Dunlop, E.S., Heino, M., Dieckmann, U., 2009. Implications of fisheries-induced evolution for stock rebuilding and recovery. Evolutionary Applications 2, 394-414. doi:10.1111/j.1752-4571.2009. 00077.x.

Fauchald, P., 2010. Predator-prey reversal: A possible mechanism for ecosystem hysteresis in the North Sea? Ecology 91, 2191-2197. doi:10.1890/09-1500.1.

Forster, J., Hirst, A.G., Atkinson, D., 2012. Warming-induced reductions in body size are greater in aquatic than terrestrial species. Proceedings of the National Academy of Sciences of the United States of America 109, 19310-19314. doi:10.1073/pnas.1210460109.

Frank, K.T., 2005. Trophic cascades in a formerly cod-dominated ecosystem. Science 308, 1621-1623. doi:10.1126/science.1113075

Frank, K.T., Petrie, B., Fisher, J.A.D., Leggett, W.C., 2011. Transient dynamics of an altered large marine ecosystem. Nature 477, 86-89. doi:10.1038/ nature10285.

Gillooly, J.F., Charnov, E.L., West, G.B., Savage, V.M., Brown, J.H., 2001. Effects of size and temperature on developmental time. Nature 417, 70-73.

Gliwicz, Z.M., 1990. Food thresholds and body size in cladocerans. Nature 343, 638-640. doi:10.1038/343638a0.

Haugen, T.0., Winfield, I.J., Vøllestad, L.A., et al., 2007. Density dependence and density independence in the demography and dispersal of pike over four decades. Ecological Monographs 77, 483-502.

van der Have, T.M., de Jong, G., 1996. Adult size in ectotherms: Temperature effects on growth and differentiation. Journal of Theoretical Biology 183, 329-340. doi:10.1006/itbi.1996.0224.

Henle, K., Davies, K., Kleyer, M., Margules, C., Settele, J., 2004. Predictors of species sensitivity to fragmentation. Biodiversity and Conservation 13, 207-251. doi:10.1023/B:BIOC.0000004319.91643.9e.

Hessen, D.O., Daufresne, M., Leinaas, H.P., 2013. Temperature-size relations from the cellular-genomic perspective. Biological Reviews 88, 476-489. doi:10.1111/ brv.12006.

Holt, R.D., Polis, G.A., 1997. A theoretical framework for intraguild predation. The American Naturalist 149, 745-764. doi:10.2307/2463547.

Hutchings, J.A., 2000. Collapse and recovery of marine fishes. Nature 406, 882-885. doi:10.1038/35022565.

Hutchings, J.A., 2005. Life history consequences of overexploitation to population recovery in Northwest Atlantic cod (Gadus morhua). Canadian Journal of Fisheries and Aquatic Sciences 62, 824-832. doi:10.1139/f05-081.

Hutchings, J.A., Fraser, D.J., 2008. The nature of fisheries- and farming-induced evolution. Molecular Ecology 17, 294-313. doi:10.1111/j.1365-294X.2007.03485.x.

Hutchings, J.A., Reynolds, J.D., 2004. Marine fish population collapses: Consequences for recovery and extinction risk. Bioscience 54, 297-309. doi:10.1641/0006-3568(2004)054[0297:MFPCCF]2.0.C0:2

Hutchinson, G.E., 1957. Concluding remarks. Cold Spring Harbor Symposia on Quantitative Biology 22, 415-427. doi:10.1101/SQB.1957.022.01.039.

Jackson, J.B.C., Kirby, M.X., Berger, W.H., et al., 2001. Historical overfishing and the recent collapse of coastal ecosystems. Science 293, 629-637. doi:10.1126 science.1059199.

Jetz, W., Carbone, C., Fulford, J., Brown, J.H., 2004. The scaling of animal space use. Science 306, 266-268. doi:10.1126/science.1102138. 
King, E.G., Roff, D.A., Fairbairn, D.J., 2011. The evolutionary genetics of acquisition and allocation in the wing dimorphic cricket, Gryllus firmus. Evolution 65, 2273-2285. doi:10.1111/j.1558-5646.2011.01296.x.

Lagler, K.F., 1968. Capture, sampling and examination of fishes. In: Ricker, W.E. (Ed.), Methods for Assessment of Fish Production in Fresh Waters, IBP Handbook, first ed. Oxford: Blackwell Publishing Ltd., pp. 1-45.

Lande, R., Arnold, S.J., 1983. The measurement of selection on correlated characters. Evolution 37, 1210-1226. doi:10.2307/2408842.

Langangen, Ø., Edeline, E., Ohlberger, J., et al., 2011. Six decades of pike and perch population dynamics in Windermere. Fisheries Research 109, 131-139. doi:10.1016/.j.fishres.2011.01.029.

Law, R., 2000. Fishing, selection, and phenotypic evolution. ICES Journal of Marine Science 57, 659-668. doi:10.1006/imsc.2000.0731.

Law, W., Salick, J., 2005. Human-induced dwarfing of Himalayan snow lotus, Saussurea laniceps (Asteraceae). Proceedings of the National Academy of the Sciences of the United States of America 102, 10218-10220. doi:10.1073/pnas. 0502931102.

Le Cren, D., 2001. The Windermere perch and pike project: An historical review. Freshwater Forum 15, 3-34.

Levins, R., 1969. Some demographic and genetic consequences of environmental heterogeneity for biological control. Bulletin of the Entomological Society of America 15, 237-240. doi:10.1093/besa/15.3.237.

Lynch, M., Walsh, B., 1998. Genetics and Analysis of Quantitative Traits, first ed. Sunderland, MA: Sinauer Associates.

Magnhagen, C., 1991. Predation risk as a cost of reproduction. Trends in Ecology and Evolution 6, 183-186. doi:10.1016/0169-5347(91)90210-0.

McAllister, M.K., Peterman, R.M., Gillis, D.M., 1992. Statistical evaluation of a large-scale fishing experiment designed to test for a genetic effect of sizeselective fishing on British Columbia pink salmon (Oncorhynchus gorbuscha). Canadian Journal of Fisheries and Aquatic Sciences 49, 1294-1304. doi:10.1139/f92-145.

Moose, S.P., Dudley, J.W., Rocheford, T.R., 2004. Maize selection passes the century mark: A unique resource for 21 st century genomics. Trends in Plant Science 9, 358-364. doi:10.1016/j.tplants.2004.05.005.

Mousseau, T.A., Roff, D.A., 1987. Natural selection and the heritability of fitness components. Heredity 59, 181-197.

Ohlberger, J., Edeline, E., Vøllestad, L.A., Stenseth, N.C., Claessen, D., 2011. Temperature-driven regime shifts in the dynamics of size-structured populations. The American Naturalist 177, 211-223. doi:10.1086/657925.

Olden, J.D., Hogan, Z.S., Zanden, M.J.V., 2007. Small fish, big fish, red fish, blue fish: Size-biased extinction risk of the world's freshwater and marine fishes. Global Ecology and Biogeography 16, 694-701. doi:10.1111/j.1466-8238.2007. 00337.x.

Olsen, E.M., Heino, M., Lilly, G.R., et al., 2004. Maturation trends indicative of rapid evolution preceded the collapse of northern cod. Nature 428, 932-935. doi:10.1038/nature02430

Owens, I.P.F., Bennett, P.M., 2000. Ecological basis of extinction risk in birds: Habitat loss versus human persecution and introduced predators. Proceedings of the National Academy of Sciences of the United States of America 97, 12144-12148. doi:10.1073/pnas.200223397.

Partridge, L., Barrie, B., Fowler, K., French, V., 1994. Evolution and development of body size and cell size in Drosophila melanogaster in response to temperature. Evolution 48, 1269-1276. doi:10.2307/2410384.

Parvinen, U., 2004. Adaptive responses to landscape disturbances: Theory. In: Ferrière, R., Dieckmann, U., Couvet, D. (Eds.), Evolutionary Conservation Biology, first ed. Cambridge MA: Cambridge University Press, pp. 265-283.

Peres, C.A., 2001. Synergistic effects of subsistence hunting and habitat fragmentation on Amazonian forest vertebrates. Conservation Biology 15, 1490-1505. doi:10.1046/j.1523-1739.2001.01089.x.

Persson, L., De Roos, A.M., 2006. Food-dependent individual growth and population dynamics in fishes. Journal of Fish Biology 69, 1-20. doi:10.1111/j.1095-8649 2006.01269.x.

Persson, L., Leonardsson, K., de Roos, A.M., Gyllenberg, M., Christensen, B., 1998. Ontogenetic scaling of foraging rates and the dynamics of a size-structured consumer-resource model. Theoretical Population Biology 54, 270-293. doi:10.1006/tpbi.1998.1380.

Peters, R.H., 1983. The Ecological Implications of Body Size, first ed. Cambridge, MA: Cambridge University Press
Pinsky, M.L., Palumbi, S.R., 2014. Meta-analysis reveals lower genetic diversity in overfished populations. Molecular Ecology 23, 29-39. doi:10.1111/mec.12509.

Pörtner, H.O., Knust, R., 2007. Climate change affects marine fishes through the oxygen limitation of thermal tolerance. Science 315, 95-97. doi:10.1126/ science. 1135471.

Pulliam, H.R., 1988. Sources, sinks, and population requlation. The American Naturalist 132, 652-661.

Purvis, A., Gittleman, J.L., Cowlishaw, G., Mace, G.M., 2000. Predicting extinction risk in declining species. Proceedings of the Royal Society of London. Series B, Biological Sciences 267, 1947-1952. doi:10.1098/rspb.2000.1234.

Reuman, D.C., Holt, R.D., Yvon-Durocher, G., 2014. A metabolic perspective on competition and body size reductions with warming. Journal of Animal Ecology 83, 59-69. doi:10.1111/1365-2656.12064.

Reznick, D.N., Bryant, M.J., Roff, D., Ghalambor, C.K., Ghalambor, D.E., 2004. Effect of extrinsic mortality on the evolution of senescence in guppies. Nature 431, 1095-1099. doi:10.1038/nature02936.

Roff, D.A., 1991. Life history consequences of bioenergetic and biomechanical constraints on migration. American Zoologist 31, 205-216. doi:10.1093/icb/ 31.1.205.

Roff, D.A., 1992. The Evolution of Life Histories: Theory and Analysis, first ed. New York: Chapman and Hall.

Roff, D.A., Fairbairn, D.A., 2001. The genetic basis of dispersal and migration, and its consequences for the evolution of correlated traits. In: Clobert, J., Danchin, É. Dhondt, A.A., Nichols, J.D. (Eds), Dispersal. Oxford: Oxford University Press, p. 452.

Ronce, O., Clobert, J., 2012. Dispersal syndromes. In: Clobert, J., Baguette, M., Benton, T.G., Bullock, J.M. (Eds.), Dispersal Ecology and Evolution, first ed. Oxford: Oxford University Press, pp. 119-138.

Shelton, P.A., Sinclair, A.F., Chouinard, G.A., Mohn, R., Duplisea, D.E., 2006. Fishing under low productivity conditions is further delaying recovery of Northwest Atlantic cod (Gadus morhua). Canadian Journal of Fisheries and Aquatic Sciences 63, 235-238. doi:10.1139/405-253.

Sibly, R.M., Atkinson, D., 1994. How rearing temperature affects optimal adult size in ectotherms. Functional Ecology 8, 486-493. doi:10.2307/2390073.

Swain, D.P., 2011. Life-history evolution and elevated natural mortality in a population of Atlantic cod (Gadus morhua). Evolutionary Applications 4, 18-29. doi:10.1111/j.1752-4571.2010.00128.x.

Tilman, D., 1982. Resource Competition and Community Structure, first ed. Princeton, NJ: Princeton University Press.

Van Allen, B.G., Dunham, A.E., Asquith, C.M., Rudolf, V.H.W., 2012. Life history predicts risk of species decline in a stochastic world. Proceedings of the Royal Society of London. Series B, Biological Sciences 279, 2691-2697. doi:10.1098/ rspb.2012.0185.

Vindenes, Y., Edeline, E., Ohlberger, J., et al., 2014. Effects of climate change on trait-based dynamics of a top predator in freshwater ecosystems. The American Naturalist 183, 243-256. doi:10.1086/674610.

Walsh, M.R., Munch, S.B., Chiba, S., Conover, D.0., 2006. Maladaptive changes in multiple traits caused by fishing: Impediments to population recovery. Ecology Letters 9, 142-148. doi:10.1111/j.1461-0248.2005.00858.x.

Williams, G.C., 1957. Pleiotropy, natural selection, and the evolution of senescence. Evolution 11, 398-411. doi:10.2307/2406060.

Wilson, D.S., Sober, E., 1994. Reintroducing group selection to the human behavioral sciences. Behavioral and Brain Sciences 17, 585-608. doi:10.1017/ S0140525X00036104.

Woodroffe, R., Ginsberg, J.R., 1998. Edge effects and the extinction of populations inside protected areas. Science 280, 2126-2128. doi:10.1126/science.280.5372. 2126.

Woodward, G., Ebenman, B., Emmerson, M., et al., 2005. Body size in ecological networks. Trends Ecology and Evolution 20, 402-409. doi:10.1016/j.tree.2005.04. 005

Zuk, M., Stoehr, A.M., 2002. Immune defense and host life history. The American Naturalist 160, S9-S22.

Zuo, W., Moses, M.E., West, G.B., Hou, C., Brown, J.H., 2011. A general model for effects of temperature on ectotherm ontogenetic growth and development. Proceedings of the Royal Society of London B: Biological Sciences 279, 1840-1846. doi:10.1098/rspb.2011.2000. 